Yaroslav Martynyshyn - Elena Khlystun - Yelena Kovalenko

\title{
THE CROSS-CULTURAL COMMUNICATIONS IN BUSINESS TRIPS: STATISTICAL MEASURES IN COORDINATES OF UKRAINE
}

The purpose of this study is to find ways to increase the effectiveness of cross-cultural communications from the standpoint of Ukrainian business. The methodology of the research is based on statistical measures; there is quantitative identification of parameters of intercultural business communication processes, their modeling, analysis and forecasting. As a result of the study, the relationship between different types of intercultural communication is determined: the transaction oriented and the relationship, formal and informal, monochrome and polychrome, expressive and restrained. Profiles and classifications of the cross-cultural communications have been constructed. The communication disagreements and corresponding reactions of Ukrainian businessmen in different countries and regions of the world have been determined. Models have been developed that reflect the patterns of the relationship between the success of communication (reaction) and intercultural differences. The obtained results can be used to substantiate the cross-cultural communication strategies of business trips.

Keywords: profile of cross-cultural communication, type of communication culture, communication disagreement and reaction, communication model, business trip

\section{Introduction}

Entering the third millennium, people have become accustomed to the idea that people live in a global world, where border crossings have not created any problems through an effective system of modern communications. In these conditions, the Ukrainian business opens up new opportunities and prospects for realizing its potential in the international arena, which, at the same time, imposes additional requirements on the professional level of businessmen and company managers. Entrepreneurs and managers must be able to operate successfully in a wide range of cultures in order to keep pace with changes taking place in the world and to remain competitive. Airlines compete with each other to provide businessmen with convenient transit and create conditions under which they would arrive at destinations fresh and rested. However, as soon as representatives of companies step into the land of a country, they are left alone with a new culture, different languages and business styles. The ability to adapt and bring one's business style in line with the style of other cultures plays an important role in their successes or failures.

In this regard, the purpose of this study is to find ways to increase the effectiveness of the cross-cultural communications, based on which Ukrainian businessmen, working in international markets could be more successful in communicating with representatives of other cultures, bypassing those sharp corners, which often become a stumbling block in the process of business travel, negotiation and conclusion of profitable contracts

An effective communication activity of abusinessman on an international scale is not a difficult task. Its solution is facilitated by the cross-cultural management, under which it is clear that the art of managing people's behavior and building relationships at the junction of business cultures, the ability to manage different attitudes, culture and habits of people in order to achieve the best business results [1]. The cross-cultural management studies how people and organizations in the global environment take cultural differences into account [2]; cooperation with representatives of another culture, maximum tolerance to differences and recognition of the priorities of foreign partners [3]; behavior of people in organizations around the world and describes organizational behavior in different countries and cultures, compares different models of this behavior and seeks to understand and improve the interaction between employees, customers, suppliers and partners from different countries and cultures [4]. Understanding approaches to doing business in different countries, people can evaluate the potential benefits and problems of cooperation with them and thus make competent decisions on how to work with a particular people and find out if there is any special need for it.

The biggest problem in establishing intercultural communications in the business trip process is cultural disagreement that may lead to misunderstandings and even conflicts. There are the following most common causes of violations of intercultural communication:

Yaroslav Martynyshyn $^{1, *}$, Elena Khlystun ${ }^{1}$, Yelena Kovalenko ${ }^{2}$

${ }^{1}$ Kiev National University of Culture and Arts, Ukraine

${ }^{2}$ National Academy of Managerial Staff of Culture and Arts, Ukraine

*E-mail of corresponding author: biguss@meta.ua 
different perceptions and interpretations of reality by representatives of different cultures [5]; differences in the stereotypes of evaluation of the same phenomena in different cultures [6]; manifestation of a sense of superiority associated with the commitment to the culture of their country [7]; semantic and technical disturbances in communication arising as a result of verbal communication and emotional communication (para verbalism), as well as differences in gestures (non-verbal) [8].

An important tool in identifying cultural differences in international business communication is a typology, which is based on the dismemberment of the communication business culture as a system for individual elements and their grouping using a generalized, idealized type. This tool is based on definition of similarities and differences between the cultural elements and it is aimed at reflecting the structure and features of business culture in different countries and regions of the world. Today, in the crosscultural management, there are four types of paired opposites of communication behavior in conducting business [9-10]:

1) focus on culture agreement or relationship. It is believed that if attention is focused on the deal, the participants think mainly about the task and if attention is focused on the relationship, then the participants are more likely to think about people. A lot of representatives of business focused on relationships believe that the focus on the deal is belligerent and aggressive;

2) a formal, elite culture with a hierarchical organization and a strict observance of differences in status and authority, or an informal, egalitarian culture, in which it is considered that all people are equal with a slight difference in status and authority. The informal behavior of some offends the perceptions of highranking representatives of elite cultures, just as their concentration on their importance may offend the feelings of representatives of the egalitarian culture;

3) monochrome culture with a rigid attitude to time and graphs, or polychrome culture with a flexible relation to time and graphs. Some countries worship the clock and value precision. Others condescendingly refer to time and graphs, they are more focused on the people who surround them. The conflict arises when those belonging to the first group consider the representatives of the other group lazy and undisciplined, whereas they are considered arrogant, bound within mandatory terms;

4) emotionally expressive, or emotionally restrained (neutral) culture. Communication of expressive people is significantly different from the communication of restrained people. This applies both to verbal communication and to non-verbal communication. These differences can lead to misunderstandings that adversely affect negotiation, transaction and management processes.

Doubles of the opposite types in cross-cultural communication are ideal types. They are sufficiently fully described in the scientific literature [11-13], however, in practice, in pure form, are rare. Today, in conditions of globalization of society, communication cultures of different countries mostly combine these cross-cultural opposites with some predominance of elements of a cultural type. However, in scientific sources there is no data on the correlation of these opposites, which makes it impossible to identify differences and build intercultural communication strategies in the process of business travel to different countries of the world:

- correlation definition of different types of intercultural communication and profiles construction and cross-cultural communication classifications of countries and regions of the world and the main communicants of Ukrainian business;

- identification of cross-cultural communication disagreements between representatives of Ukrainian business and business representatives from foreign partner countries;

- measures identification of cross-cultural communication reactions of Ukrainian entrepreneurs and managers on intercultural differences with foreign partners;

- $\quad$ statistical development and mathematical tools for modeling, analyzing and predicting the effectiveness of cross-cultural communications of Ukrainian business, depending on the level of intercultural differences.

\section{Methodology}

The methodological basis of the research is the dialectical principle of cognition, systematic and cultural approaches, statistical methods of surveying, expert evaluation, analytical grouping, mathematical modeling, analysis and prediction of cross-cultural communication processes, as well as the fundamental provisions of the theory of management in the intercultural environment. Based on the objectives of the study, its main focus is on the construction of the cross-cultural communication profiles, identification of the cultural differences and identification of patterns of their influence on the formation of communication responses, which will serve as the basis for developing the cross-cultural strategies for behavior of representatives of Ukrainian business.

The research methodology includes the following steps.

1. Collection of statistical data about the research object, which involves a survey of representatives of Ukrainian business and the evaluation of the structure of the four duplex opposite types of communication (D and U; F and I; M and P; E and N) in Ukraine and in foreign countries (where the business trips were carried out), as well as evaluation of the success rate of communications are reactions (R) of Ukrainian businessmen to cross-cultural differences. 
The structure of the pair of opposing types of cross-cultural communication for each respondent is estimated in units of unit:

$\mathrm{D}$ and $\mathrm{U}$ - the share of concentration on the transaction and the relationship $(\mathrm{D}+\mathrm{U}=1)$;

$\mathrm{F}$ and I - the proportion of formalities and informality $(\mathrm{F}+\mathrm{I}=1)$;

$\mathrm{M}$ and $\mathrm{P}$ - the proportion of monochrome and polychrome $(\mathrm{M}+\mathrm{P}=1)$;

$\mathrm{E}$ and $\mathrm{N}$ - the share of expressiveness and restraint, neutrality $(\mathrm{E}+\mathrm{N}=1)$.

The reaction to cultural differences, or the level of success of cross-cultural communication (R) for each respondent is estimated on a 100-point scale.

The study covers 20 countries and regions and 716 respondents in particular: Baltic - 37; Belarus - 42; Canada 34; China - 32; Czechia - 38; France - 36; Germany - 35; Hungary - 34; India - 32; Italy - 33; Moldova - 38; Poland - 36; Romania - 35; Russia - 44; Scandinavia - 32; Slovakia - 36; Spain - 33; Turkey - 37; UK - 34; USA - 38.

2. Summarizing statistical data and calculating general indicators of the cross-cultural communication across countries and regions of the world:

a) systematization of statistical data by country and regions;

b) calculation of average values the structure parameters of the pair of communication culture opposing pairs:

$\mathrm{CD}=\Sigma \mathrm{D} / \mathrm{Q}, \mathrm{CU}=1-\mathrm{CD}$;

$\mathrm{CF}=\Sigma \mathrm{F} / \mathrm{Q}, \mathrm{CI}=1-\mathrm{CF}$,

$\mathrm{CM}=\Sigma \mathrm{M} / \mathrm{Q}, \mathrm{CP}=1-\mathrm{CM}$,

$\mathrm{CE}=\Sigma \mathrm{E} / \mathrm{Q}, \mathrm{CN}=1-\mathrm{CE}$,

where $\mathrm{Q}$ - the number of respondents in a particular country or region;

c) calculation of average values of the reaction (success) of the cross-cultural communication (YR) in the studied countries:

$\mathrm{YR}=\Sigma \mathrm{R} / \mathrm{Q}$.

3. Construction of profiles and classifications of crosscultural communication in countries and regions of the world from the standpoint of Ukrainian entrepreneurs and managers. The profile of the country's communication culture consists of the average values of the indicators of the structure of the pair of intercultural communication opposing types:

$\{\mathrm{CD}$ and $\mathrm{CU} ; \mathrm{CF}$ and $\mathrm{CI} ; \mathrm{CM}$ and $\mathrm{CP} ; \mathrm{CE}$ and $\mathrm{CN}\}$.

4. Identify cross-cultural communication disagreements across countries and regions. The average values of intercultural communication differences in each pairwise opposite type of the cross-cultural communication $(\Delta \mathrm{CDU} ; \Delta \mathrm{CFI} ; \Delta \mathrm{CMP}$;
$\Delta \mathrm{CEN})$ and in general $(\Delta \mathrm{C})$ of one or another country are calculated according to the following formulas:

$\Delta \mathrm{CDU}=|\mathrm{CD} o-\mathrm{CD} i|$ or $|\mathrm{CU} o-\mathrm{CU} i|$, $\Delta \mathrm{CFI}=|\mathrm{CF} o-\mathrm{CF} i|$ or $|\mathrm{CI} o-\mathrm{CI} i|$ $\Delta \mathrm{CMP}=|\mathrm{CM} o-\mathrm{CM} i|$ or $|\mathrm{CP} o-\mathrm{CP} i|$, $\Delta \mathrm{CEN}=|\mathrm{CE} o-\mathrm{CE} i|$ or $|\mathrm{CN} o-\mathrm{CN} i|$, $\Delta \mathrm{C}=(\Delta \mathrm{CDU}+\Delta \mathrm{CFI}+\Delta \mathrm{CMP}+\Delta \mathrm{CEN}) / 4$,

where $o, i$ - indexes that represent indicators relating respectively to Ukraine and the foreign country.

5. Analytical grouping of countries and regions by the middle level of the cross-cultural communication disagreement $(\Delta \mathrm{C})$ and revealing patterns of its influence on the success of communication (YR) of Ukrainian businessmen:

$\Delta \mathrm{C} \rightarrow \mathrm{YR}$.

6. Construction of statistical and mathematical models of communication of the cross-cultural communication reactions across countries and regions of the world depend on the level of intercultural differences:

$\tilde{\mathrm{R}}=\mathrm{k}(\Delta \mathrm{DU}, \Delta \mathrm{FI}, \Delta \mathrm{MP}, \Delta \mathrm{EN})$,

where $\mathrm{R}$ - the effective indicator of the model of a particular country (the success of communication, or the reaction of representatives of the Ukrainian business to the cross-cultural differences), in points;

$\Delta \mathrm{DU}, \Delta \mathrm{FI}, \Delta \mathrm{MP}, \Delta \mathrm{EN}$ - factor indicators of the model (cross-cultural differences), in parts of unit. They are determined by each respondent according to the following formulas:

$\Delta \mathrm{DU}=|\mathrm{D} o-\mathrm{D} i|$ or $|\mathrm{U} o-\mathrm{U} i|$, $\Delta \mathrm{FI}=|\mathrm{F} o-\mathrm{F} i|$ or $|\mathrm{I} o-\mathrm{I} i|$, $\triangle \mathrm{MP}=|\mathrm{M} o-\mathrm{M} i|$ or $|\mathrm{P} o-\mathrm{P} i|$ $\Delta \mathrm{EN}=|\mathrm{E} o-\mathrm{E} i|$ or $|\mathrm{N} o-\mathrm{N} i|$.

The construction of models involves the following steps:

A. Verification of consolidated and systematic statistical sample data for their compliance with established requirements for statistical and mathematical modeling and representativeness. The results of such verification have shown that information is sufficient, both in terms of the number of units and the variation of attributes and in harmony of its aggregates with normal distribution, and also whether it is representative of the general population [14].

The test showed that the source information is sufficient, both in the number of observation units $(\mathrm{Q} / 4 \geq 8)$ and in the variation of the resultant and factor characteristics $(\mathrm{V}>10 \%)$, and in the harmony of its aggregates with normal distribution $(\tau<3 \sigma)$; it is also representative of the general population, since its actual error, at a given probability level of 0.95 , does not exceed the marginal $(\Delta \mathrm{f}<\Delta \mathrm{lim})$. 
Table 1 Profiles of cross-cultural business communications

\begin{tabular}{|c|c|c|c|c|c|c|c|c|}
\hline \multirow{3}{*}{$\begin{array}{l}\text { Country, } \\
\text { region }\end{array}$} & \multicolumn{8}{|c|}{ Profile } \\
\hline & \multicolumn{2}{|c|}{$\mathrm{CDU}$} & \multicolumn{2}{|c|}{ CFI } & \multicolumn{2}{|c|}{ CMP } & \multicolumn{2}{|c|}{$\mathrm{CEN}$} \\
\hline & CD & $\mathrm{CU}$ & $\mathrm{CF}$ & CI & $\mathrm{CM}$ & $\mathrm{CP}$ & $\mathrm{CE}$ & $\mathrm{CN}$ \\
\hline Ukraine & 0.41 & 0.59 & 0.67 & 0.33 & 0.56 & 0.44 & 0.61 & 0.39 \\
\hline Baltic & 0.83 & 0.17 & 0.58 & 0.42 & 0.74 & 0.26 & 0.45 & 0.55 \\
\hline Belarus & 0.38 & 0.62 & 0.71 & 0.29 & 0.60 & 0.40 & 0.59 & 0.41 \\
\hline Canada & 0.88 & 0.12 & 0.05 & 0.95 & 0.91 & 0.09 & 0.67 & 0.33 \\
\hline China & 0.02 & 0.98 & 0.98 & 0.02 & 0.96 & 0.04 & 0.01 & 0.99 \\
\hline Czechia & 0.66 & 0.34 & 0.72 & 0.28 & 0.75 & 0.25 & 0.62 & 0.38 \\
\hline France & 0.84 & 0.16 & 0.83 & 0.17 & 0.77 & 0.23 & 0.91 & 0.09 \\
\hline Germany & 0.92 & 0.08 & 0.90 & 0.10 & 0.93 & 0.07 & 0.32 & 0.68 \\
\hline Hungary & 0.67 & 0.33 & 0.55 & 0.45 & 0.64 & 0.36 & 0.80 & 0.20 \\
\hline India & 0.01 & 0.99 & 0.99 & 0.01 & 0,03 & 0.97 & 0.00 & 1.00 \\
\hline Italy & 0.87 & 0.13 & 0.61 & 0.39 & 0.74 & 0.26 & 0.96 & 0.04 \\
\hline Moldova & 0.34 & 0.66 & 0.84 & 0.16 & 0.36 & 0.64 & 0.89 & 0.11 \\
\hline Poland & 0.49 & 0.51 & 0.57 & 0.43 & 0.64 & 0.36 & 0.52 & 0.48 \\
\hline Romania & 0.37 & 0.63 & 0.88 & 0.12 & 0.39 & 0.61 & 0.96 & 0.04 \\
\hline Russia & 0.39 & 0.61 & 0.73 & 0.27 & 0.61 & 0.39 & 0.67 & 0.33 \\
\hline Scandinavia & 0.91 & 0.09 & 0.41 & 0.59 & 0.84 & 0.16 & 0.35 & 0.65 \\
\hline Slovakia & 0.51 & 0.49 & 0.62 & 0.38 & 0.66 & 0.34 & 0.56 & 0.44 \\
\hline Spain & 0.76 & 0.24 & 0.51 & 0.49 & 0.74 & 0.26 & 0.87 & 0.13 \\
\hline Turkey & 0.02 & 0.98 & 0.98 & 0.02 & 0.01 & 0.99 & 0.99 & 0.01 \\
\hline UK & 0.93 & 0.07 & 0.91 & 0.09 & 0.92 & 0.08 & 0.28 & 0.72 \\
\hline USA & 0.95 & 0.05 & 0.04 & 0.96 & 0.94 & 0.06 & 0.63 & 0.37 \\
\hline
\end{tabular}

Therefore, this sample information can be used in modeling the interconnections of cross-cultural communication reactions and intercultural differences with dissemination and interpretation of results for the entire general population of Ukrainian business (error up to 3\%).

B. Detection of the form of the cause-and-effect relationship between factor and resultant features carried out by means of grouping and graphing methods and constructing a model in a general symbolic form.

As confirmed by analysis, the relationship between the performance indicator $(\mathrm{R})$ and the factors $(\Delta \mathrm{DU}, \Delta \mathrm{FI}$, $\Delta \mathrm{MP}, \Delta \mathrm{EN}$ ) is inverse, and the form of communication is close to the linear.

Consequently, the general form of statistical and mathematical models will be the following:

$\tilde{\mathrm{R}}=100-a_{1} \Delta \mathrm{DU}-a_{2} \Delta \mathrm{FI}-a_{3} \Delta \mathrm{MP}-a_{4} \Delta \mathrm{EN}$

where 100, $a_{1}, a_{2}, a_{3}, a_{4}$ - models' options, apart: 100 - free member (maximum value of communication success); $a_{1} \ldots a_{4}$ - coefficients of regression.

C. Modelling in numerical form. This work is carried out on a computer and includes correlation calculations and evaluation of reliability of the communication characteristics: the numerical values of regression coefficients $\left(a_{1}, a_{2}, a_{3}, a_{4}\right)$, multiple and partial correlation coefficients $\left(r, r_{1}, r_{2}, r_{3}, r_{4}\right)$ are determined $\left(d, d_{1}, d_{2}, d_{3}, d_{4}\right)$, the actual values of the Fisher $(F)$ and Student criteria $\left(t_{1}, t_{2}, t_{3}, t_{4}\right)$. With help of the $t$ - and $F$-criteria one can evaluate the reliability of the regression coefficients and the model as a whole. Based on the correlation coefficients, the binding force is estimated and the determination coefficients are the proportion of the variation of the resultant characteristics, which is determined by influence of the factor characteristics.

7. Statistical and mathematical analysis and forecasting. With help of developed numerical models it is possible to carry out a deep analysis of the effectiveness (success) of cross-cultural communications. In particular, using the regression coefficients $\left(a_{1}, a_{2}, a_{3}, a_{4}\right)$. The degree of influence of the corresponding factor $(\Delta \mathrm{DU}, \Delta \mathrm{FI}, \Delta \mathrm{MP}, \Delta \mathrm{EN})$ on the resultant indicator $(\mathrm{R})$ has been determined; in the scores: with the change of the individual factor per unit, the resultant indicator will change to the corresponding factor. Knowing the magnitude of the variation of each factor, the maximum change in the effective index has been found and by the determination coefficients $\left(d, d_{1}, d_{2}, d_{3}, d_{4}\right)$ there is a conclusion on the proportion of its variation due to the influence of all or a particular factor included in the model. On the basis of models, it is also possible to predict cross-cultural communication reactions. 
Table 2 Distribution of countries and regions for dual opposite types of communication culture

\begin{tabular}{|c|c|c|c|}
\hline $\begin{array}{l}\text { Predominant } \\
\text { type of } \\
\text { culture }\end{array}$ & $\begin{array}{c}\text { Specific } \\
\text { weight }\end{array}$ & Country, region & Ctype \\
\hline \multicolumn{4}{|c|}{ Focus on the deal / Orientation on the relationship } \\
\hline \multirow{3}{*}{$\begin{array}{l}\text { Culture } \\
\text { orientated for } \\
\text { an agreement }\end{array}$} & High & USA (0.95), UK (0.93), Germany (0.92), Scandinavia (0.91) & $\mathrm{CD}=0.93$ \\
\hline & Average & Canada (0.88), Italy (0.87), France (0.84), Baltic (0.83) & $\mathrm{CD}=0.85$ \\
\hline & Low & Spain (0.76), Hungary (0.67), Czech (0.66), Slovakia (0.51) & $\mathrm{CD}=0.65$ \\
\hline \multirow{2}{*}{$\begin{array}{l}\text { Culture } \\
\text { focused on } \\
\text { relationship }\end{array}$} & High & India (0.99), China (0.99), Turkey (0.98) & $\mathrm{CU}=0.99$ \\
\hline & Low & $\begin{array}{l}\text { Moldova (0.66), Romania (0.63), Belarus (0.62), Russia (0.61), Ukraine (0.59), Poland } \\
(0.51)\end{array}$ & $\mathrm{CU}=0.60$ \\
\hline \multicolumn{4}{|c|}{ Formal culture / Informal culture } \\
\hline \multirow{3}{*}{$\begin{array}{l}\text { Formal } \\
\text { culture }\end{array}$} & & India (0.99), China (0.98), Turkey (0.98), UK (0.91), Germany (0.90) & $\mathrm{CF}=0.95$ \\
\hline & $\begin{array}{l}\text { High } \\
\text { Average }\end{array}$ & $\begin{array}{l}\text { Romania (0.88), Moldova (0.84), France (0.83), Russia (0.73), Czechia (0.72), Belarus } \\
(0.71) \text {, Ukraine (0.67) }\end{array}$ & $\mathrm{CF}=0.77$ \\
\hline & Low & $\begin{array}{l}\text { Slovakia (0.62), Italy (0.61), Baltic (0.58), Poland (0.57), } \\
\text { Hungary (0.55), Spain (0.51) }\end{array}$ & $\mathrm{CF}=0.57$ \\
\hline \multirow{2}{*}{$\begin{array}{l}\text { Informal } \\
\text { culture }\end{array}$} & High & USA (0.96), Canada (0.95) & $\mathrm{CI}=0.96$ \\
\hline & Low & Scandinavia $(0.59)$ & $\mathrm{CI}=0.59$ \\
\hline \multicolumn{4}{|c|}{ Monochrome Culture / Polychrome Culture } \\
\hline \multirow{3}{*}{$\begin{array}{l}\text { Monochrome } \\
\text { culture }\end{array}$} & High & China (0.96), USA (0.94), Germany (0.93), UK (0.92), Canada (0.91), Scandinavia (0.84) & $\mathrm{CM}=0.90$ \\
\hline & Average & France (0.77), Czech (0.75), Italy (0.74), Spain (0.74), Baltic (0.74) & $\mathrm{CM}=0.75$ \\
\hline & Low & Slovakia (0.66), Poland (0.64), Hungary (0.64), Russia (0.61), Belarus (0.60), Ukraine (0.56) & $\mathrm{CM}=0.62$ \\
\hline \multirow{2}{*}{$\begin{array}{l}\text { Polychrome } \\
\text { culture }\end{array}$} & High & Turkey (0.99), India (0.97) & $\mathrm{CP}=0.98$ \\
\hline & Low & Moldova (0.64), Romania (0.61) & $\mathrm{CP}=0.63$ \\
\hline \multicolumn{4}{|c|}{ Expressive culture / Neutral culture } \\
\hline \multirow{4}{*}{$\begin{array}{l}\text { Expressive } \\
\text { culture }\end{array}$} & & Turkey (0.99), Italy (0.96), Romania (0.96), France (0.91) & $\mathrm{CE}=0.96$ \\
\hline & High & Moldova (0.89), Spain (0.87), Hungary $(0.80)$ & $\mathrm{CE}=0.85$ \\
\hline & $\begin{array}{l}\text { Average } \\
\text { Low }\end{array}$ & Canada (0.67), Russia (0.67), USA (0.63), Czechia (0.62), & $\mathrm{CE}=0.61$ \\
\hline & & Ukraine (0.61), Belarus (0.59), Slovakia (0.56), Poland (0.52) & \\
\hline \multirow{2}{*}{$\begin{array}{l}\text { Neutral } \\
\text { culture }\end{array}$} & High & India (1.00), China (0.99) & $\mathrm{CN}=1.00$ \\
\hline & Low & UK (0.72), Germany (0.68), Scandinavia (0.65), Baltic (0.55) & $\mathrm{CN}=0.65$ \\
\hline
\end{tabular}

Substituting specific values of factor-factors in the model $(\Delta \mathrm{DU}, \Delta \mathrm{FI}, \Delta \mathrm{MP}, \Delta \mathrm{EN})$, the expected values of the effective index have been predicted $(R)$.

\section{Results and discussion}

The basic result of the research, which is based on the following results, is the construction of profiles of the crosscultural communications of the countries and regions of the world, with which the Ukrainian business interacts. As can be seen from Table 1, profiles by country and region are different. In some countries, they are very high, while in some, on the other hand, are very low, while in others are at an average level. However, this does not in any way mean that some of the crops are better, and some are worse. There is no absolute standard of correctness or perfection that can be applied to assessment of the communication behavior. Cultural differences are neither beautiful nor bad, they are just other; although some cultural behavior may be easier than others to adapt to specific environmental conditions. Ukrainian communication culture is no closer to an ideal than any other culture, although it may be better for Ukrainian entrepreneurs and managers. Thus, ethno-relativism is the assumption that communication cultures can be understood only relative to one another, and specific behavior - only within the context of a cultural context, must be fundamental in understanding of the crosscultural communications.

However, there are not only differences but also some similarities between the communication cultures of the countries and regions of the world, which allow them to be classified according to cultural types (see Tables 2 and 3).

India and China are representatives of the oldest eastern civilizations, as well as Turkey, a representative of the Muslim world (see Table 3, Classes Nos. 1, 2, 3 ), the most visible communication cultures, from the totality of the studied countries. Communication cultures of these three countries are as much as possible oriented on interrelations, formality, elitism, strict adherence to 
Table 3 Distribution of countries and regions by combined classes communication culture

\begin{tabular}{|c|c|c|c|c|}
\hline No & $\begin{array}{c}\text { Classes } \\
\text { of communication culture }\end{array}$ & $\begin{array}{l}\text { Formula of } \\
\text { combinations }\end{array}$ & Country, region & Ccombin \\
\hline 1 & $\begin{array}{l}\text { Maximally oriented on the relationship, formality, } \\
\text { polychrome, neutrality }\end{array}$ & $\mathrm{U}+\mathrm{F}+\mathrm{P}+\mathrm{N}$ & India $(0.99 ; 0.99 ; 0.97 ; 1.00)$ & 0.99 \\
\hline 2 & $\begin{array}{l}\text { Maximally oriented on the relationship, formality, } \\
\text { monochrome, neutrality }\end{array}$ & $\mathrm{U}+\mathrm{F}+\mathrm{M}+\mathrm{N}$ & China $(0.99 ; 0.98 ; 0.96 ; 0.99)$ & 0.98 \\
\hline 3 & $\begin{array}{l}\text { Maximally oriented on the relationship, formality, } \\
\text { polychrome, expressiveness }\end{array}$ & $\mathrm{U}+\mathrm{F}+\mathrm{P}+\mathrm{E}$ & Turkey $(0.98 ; 0.98 ; 0.99 ; 0.99)$ & 0.99 \\
\hline $3 \mathrm{a}$ & $\begin{array}{l}\text { Moderately oriented on relationships, formality, } \\
\text { polychrome; as expressive as possible }\end{array}$ & $\mathrm{U}+\mathrm{F}+\mathrm{P}+\mathrm{E}$ & $\begin{array}{l}\text { Romania }(0.63 ; 0.88 ; 0.61 ; 0.96) \\
\text { Moldova }(0.66 ; 0.84 ; 0.64 ; 0.89)\end{array}$ & 0.76 \\
\hline 4 & $\begin{array}{l}\text { Maximally focused on the deal, informality, } \\
\text { monochrome; moderately expressive }\end{array}$ & $\mathrm{D}+\mathrm{I}+\mathrm{M}+\mathrm{E}$ & $\begin{array}{l}\text { USA }(0.95 ; 0.96 ; 0.94 ; 0.63) \\
\text { Canada }(0.88 ; 0.95 ; 0.91 ; 0.67)\end{array}$ & 0.86 \\
\hline 5 & $\begin{array}{l}\text { Maximum approximation; moderately informal, } \\
\text { monochrome, neutral }\end{array}$ & $\mathrm{D}+\mathrm{I}+\mathrm{M}+\mathrm{N}$ & Scandinavia $(0.91 ; 0.59 ; 0.84 ; 0.65)$ & 0.75 \\
\hline 6 & $\begin{array}{l}\text { Maximum focused on the deal, formality, } \\
\text { monochrome; moderately neutral }\end{array}$ & $\mathrm{D}+\mathrm{F}+\mathrm{M}+\mathrm{N}$ & $\begin{array}{l}\text { UK }(0.93 ; 0.91 ; 0.92 ; 0.72) \\
\text { Germany }(0.92 ; 0.90 ; 0.93 ; 0.68)\end{array}$ & 0.86 \\
\hline $6 \mathrm{a}$ & $\begin{array}{l}\text { Moderately focused on the deal, formality, } \\
\text { monochrome, neutrality }\end{array}$ & $\mathrm{D}+\mathrm{F}+\mathrm{M}+\mathrm{N}$ & Baltic $(0.83 ; 0.58 ; 0.74 ; 0.55)$ & 0.68 \\
\hline 7 & $\begin{array}{l}\text { Moderately oriented on the relationship, formality, } \\
\text { monochrome, expressiveness }\end{array}$ & $\mathrm{U}+\mathrm{F}+\mathrm{M}+\mathrm{E}$ & $\begin{array}{l}\text { Ukraine }(0.59 ; 0.67 ; 0.56 ; 0.61) \\
\text { Belarus }(0.62 ; 0.71 ; 0.60 ; 0.59) \\
\text { Russia }(0.61 ; 0.73 ; 0.61 ; 0.67) \\
\text { Poland }(0.51 ; 0.57 ; 0.64 ; 0.52)\end{array}$ & 0.61 \\
\hline 8 & $\begin{array}{l}\text { Moderately focused on the deal, formality, } \\
\text { monochrome, expressiveness }\end{array}$ & $\mathrm{D}+\mathrm{F}+\mathrm{M}+\mathrm{E}$ & $\begin{array}{l}\text { Slovakia }(0.51 ; 0.62 ; 0.66 ; 0.56) \\
\text { Czech }(0.66 ; 0.72 ; 0.75 ; 0.62) \\
\text { Hungary }(0.67 ; 0.55 ; 0.64 ; 0.80)\end{array}$ & 0.65 \\
\hline $8 \mathrm{a}$ & $\begin{array}{l}\text { Moderately focused on the deal, formality, } \\
\text { monochrome; as expressive as possible }\end{array}$ & $\mathrm{D}+\mathrm{F}+\mathrm{M}+\mathrm{E}$ & $\begin{array}{l}\text { France }(0.84 ; 0.83 ; 0.77 ; 0.91) \\
\text { Italy }(0.87 ; 0.61 ; 0.74 ; 0.96) \\
\text { Spain }(0.76 ; 0.51 ; 0.74 ; 0.87)\end{array}$ & 0.78 \\
\hline
\end{tabular}

hierarchy and differences in the status and power of communicants. In addition, India and Turkey have the most polychrome cultures, which do not pay much attention to the time and schedule of work, while China is the bearer of a rigidly monochromatic culture. Still, the communication culture of India and China is as restrained, neutral, while Turkey, on the contrary, is as expressive as possible.

Further, among the studied countries and regions, the United States, Canada, Great Britain and Germany (see Table 3, Classes Nos. 4, 6), which are as much as possible focused on the deal and monochrome, are particularly distinguished. The differences between them are that in the US and Canada, the business communication culture is at most informal, egalitarian and moderately expressive, while in the UK and Germany it is as formalized and moderately neutral.

The cultures of the Scandinavian and Baltic countries are somewhat similar to the communication cultures of the United States, Germany and among themselves (see Table 3, Classes 5, 6a), which are equally moderately neutral. However, Scandinavian countries, compared to the Baltic countries, are much more focused on the deal and monochrome. The main difference between them is that Scandinavian communication culture is moderately informal and similar, on this basis, to the culture of the United States, while the Baltic is moderately formal and more similar to the culture of Germany.

Communication cultures of Romania, Moldova, France, Italy and Spain are characterized by a maximum level of expressiveness (see Table 3, Classes Nos. 3a, 8a), and they are similar to the culture of Turkey. However, in all the other parameters with Turkey's culture, only Romania and Moldova are the most correlated, which are moderately oriented on interrelations, formality and polychrome. France, Italy and Spain, according to their profiles, have the highest resemblance to Slovakia, the Czech Republic and Hungary (see Class No. 8), but, in contrast to the latter, they are characterized by significantly higher indicators of orientation to the agreement, formality, monochrome and expressiveness.

The cultures of business communication in Ukraine, Belarus, Russia and Poland (see Table 3, Grade 7), which are moderately oriented towards interrelations, formalities, monochrome and expressiveness, are very similar to the cultures of Slovakia, the Czech Republic and Hungary. The only significant difference is that the former are more focused on the relationship and the other on the deal.

Nevertheless, despite some similarities in profiles the of communication cultures of countries and regions of the 
Table 4 The cross-cultural communication disagreements and reactions

\begin{tabular}{|c|c|c|c|c|c|c|}
\hline \multirow{2}{*}{$\begin{array}{c}\text { Country, } \\
\text { region }\end{array}$} & \multicolumn{5}{|c|}{ Differences } & \multirow{2}{*}{$\begin{array}{c}\text { Reaction } \\
\text { YR }\end{array}$} \\
\hline & $\Delta \mathrm{CDU}$ & $\Delta \mathrm{CFI}$ & $\Delta \mathrm{CMP}$ & $\triangle \mathrm{CEN}$ & $\Delta \mathrm{C}$ & \\
\hline Baltic & 0.42 & 0.09 & 0.18 & 0.16 & 0.21 & 59.8 \\
\hline Belarus & 0.03 & 0.04 & 0.04 & 0.02 & 0.03 & 92.1 \\
\hline Canada & 0.47 & 0.62 & 0.35 & 0.06 & 0.38 & 35.5 \\
\hline China & 0.39 & 0.31 & 0.40 & 0.60 & 0.43 & 23.1 \\
\hline Czechia & 0.22 & 0.05 & 0.19 & 0.01 & 0.12 & 75.2 \\
\hline France & 0.43 & 0.16 & 0.21 & 0.30 & 0.28 & 49.8 \\
\hline Germany & 0.51 & 0.23 & 0.37 & 0.29 & 0.35 & 40.1 \\
\hline Hungary & 0.26 & 0.12 & 0.08 & 0.19 & 0.16 & 67.1 \\
\hline India & 0.40 & 0.32 & 0.53 & 0.61 & 0.47 & 18.5 \\
\hline Italy & 0.46 & 0.06 & 0.18 & 0.35 & 0.26 & 54.0 \\
\hline Moldova & 0.07 & 0.17 & 0.20 & 0.28 & 0.18 & 66.4 \\
\hline Poland & 0.08 & 0.10 & 0.08 & 0.09 & 0.09 & 76.7 \\
\hline Romania & 0.04 & 0.21 & 0.17 & 0.35 & 0.19 & 62.2 \\
\hline Russia & 0.02 & 0.06 & 0.05 & 0.06 & 0.04 & 86.9 \\
\hline Scandinavia & 0.50 & 0.26 & 0.28 & 0.26 & 0.32 & 45.3 \\
\hline Slovakia & 0.10 & 0.05 & 0.10 & 0.05 & 0.08 & 79.8 \\
\hline Spain & 0.35 & 0.16 & 0.18 & 0.26 & 0.24 & 58.1 \\
\hline Turkey & 0.39 & 0.31 & 0.55 & 0.38 & 0.41 & 30.2 \\
\hline UK & 0.52 & 0.24 & 0.36 & 0.33 & 0.36 & 36.7 \\
\hline USA & 0.54 & 0.63 & 0.38 & 0.02 & 0.39 & 32.3 \\
\hline
\end{tabular}

Table 5 Grouping of countries and regions at the level of the cross-cultural differences and revealing their influence on communication reactions

\begin{tabular}{rlcc}
\hline & Groups by level of disagreement & \multicolumn{2}{c}{ Average value } \\
\cline { 3 - 4 } to 0.10 & (Belarus, Russia, Slovakia, Poland) & differences $\Delta \mathrm{C}$ & reactions YR \\
$0.11-0.20$ & (Czechia, Hungary, Moldova, Romania) & 0.06 & 83.9 \\
$0.21-0.30$ & (Baltic, Spain, Italy, France) & 0.16 & 67.7 \\
$0.31-0.40$ & (Scandinavia, Germany, UK, Canada, USA) & 0.25 & 55.4 \\
over 0.40 & (Turkey, China, India) & 0.36 & 38.0 \\
\hline
\end{tabular}

world, there are still differences between them, which form the corresponding reactions of Ukrainian entrepreneurs and managers in the process of business travel (see Table 4). The greatest discrepancies have been with the cultures of India, China and Turkey and the smallest with Belarus, Russia, Slovakia and Poland.

The analytical grouping of countries and regions according to the level of cross-cultural differences confirms the existence of a logical inverse relationship between the size of disagreements and the success of communications (see Table 5).

More deeply, the patterns of influence of the crosscultural differences on the reaction of the Ukrainian businessmen can be analyzed and predicted on the basis of developed statistical and mathematical models (see Table 6), which are sufficiently reliable for practical use, since the actual values of the $\boldsymbol{t}$ - and $\boldsymbol{F}$-criteria have appeared many times more critical values. The multiple correlation coefficients of these models $(\boldsymbol{r}=0.82 \ldots 0.90)$ indicate a strong link between the effective $(\mathrm{R})$ and the factor $(\Delta \mathrm{DU}, \Delta \mathrm{FI}, \Delta \mathrm{MP}, \Delta \mathrm{EN})$ signs.

With decreasing intercultural communication differences $\Delta \mathrm{DU}, \Delta \mathrm{FI}, \Delta \mathrm{MP}, \Delta \mathrm{EN}$ by 0.1 , the success of communication $\mathrm{R}$ in the aggregate of the studied countries and regions will increase on average: due to each factor by: $\Delta \mathrm{R}_{1}=0.1 \cdot a_{1}=4.7 \ldots 7.9 ; \Delta \mathrm{R}_{2}=0.1 \cdot a_{2}=2.8$ $\ldots 7.3 ; \Delta \mathrm{R}_{3}=0.1 \cdot a_{3}=3.4 \ldots 7.1 ; \Delta \mathrm{R}_{4}=0.1 \cdot a_{4}=2.6 \ldots 6.2$ points; by all factors at $\Delta \mathrm{R}=13.5 \ldots 28.5$ points. Variation in the success of communication is determined by the complex of these factors, on average, by $\boldsymbol{d}=67 \ldots 82 \%$, including by some factors: $\boldsymbol{d}_{1}=0.20 \ldots 0.25 ; \boldsymbol{d}_{2}=0.11 \ldots 0.21 ; \boldsymbol{d}_{3}=0.13$ $\ldots 0.21 ; \boldsymbol{d}_{4}=0.12 \ldots 0.19 \%$.

Only one of the possible combinations of the changing cultural differences across the whole of the studied 
Table 6 Statistical and mathematical models of communications of communication reactions depending on the crosscultural differences

\begin{tabular}{|c|c|c|c|c|c|c|}
\hline \multirow{2}{*}{ Country, region } & \multirow{2}{*}{ Model } & \multicolumn{5}{|c|}{ The coefficients of determination } \\
\hline & & d & d1 & $\mathrm{d} 2$ & d3 & $\mathrm{d} 4$ \\
\hline Baltic & $\tilde{\mathrm{R}}=100-55.4 \Delta \mathrm{DU}-49.4 \Delta \mathrm{FI}-43.5 \Delta \mathrm{MP}-29.7 \Delta \mathrm{EN}$ & 0.77 & 0.22 & 0.19 & 0.17 & 0.19 \\
\hline Belarus & $\tilde{\mathrm{R}}=100-65.3 \Delta \mathrm{DU}-62.9 \Delta \mathrm{FI}-60.5 \Delta \mathrm{MP}-53.2 \Delta \mathrm{EN}$ & 0.82 & 0.22 & 0.21 & 0.21 & 0.18 \\
\hline Canada & $\tilde{\mathrm{R}}=100-48.2 \Delta \mathrm{DU}-41.8 \Delta \mathrm{FI}-40.2 \Delta \mathrm{MP}-30.6 \Delta \mathrm{EN}$ & 0.70 & 0.21 & 0.18 & 0.18 & 0.13 \\
\hline China & $\tilde{\mathrm{R}}=100-61.0 \Delta \mathrm{DU}-37.7 \Delta \mathrm{FI}-34.1 \Delta \mathrm{MP}-46.7 \Delta \mathrm{EN}$ & 0.69 & 0.23 & 0.14 & 0.13 & 0.19 \\
\hline Czechia & $\tilde{\mathrm{R}}=100-54.9 \Delta \mathrm{DU}-52.8 \Delta \mathrm{FI}-50.8 \Delta \mathrm{MP}-44.7 \Delta \mathrm{EN}$ & 0.79 & 0.21 & 0.21 & 0.20 & 0.17 \\
\hline France & $\tilde{\mathrm{R}}=100-49.1 \Delta \mathrm{DU}-47.3 \Delta \mathrm{FI}-45.4 \Delta \mathrm{MP}-40.0 \Delta \mathrm{EN}$ & 0.78 & 0.21 & 0.20 & 0.19 & 0.18 \\
\hline Germany & $\tilde{\mathrm{R}}=100-49.9 \Delta \mathrm{DU}-43.2 \Delta \mathrm{FI}-41.6 \Delta \mathrm{MP}-31.6 \Delta \mathrm{EN}$ & 0.71 & 0.21 & 0.18 & 0.18 & 0.14 \\
\hline Hungary & $\tilde{\mathrm{R}}=100-63.3 \Delta \mathrm{DU}-58.8 \Delta \mathrm{FI}-54.2 \Delta \mathrm{MP}-27.1 \Delta \mathrm{EN}$ & 0.77 & 0.22 & 0.20 & 0.18 & 0.17 \\
\hline India & $\tilde{\mathrm{R}}=100-64.5 \Delta \mathrm{DU}-27.9 \Delta \mathrm{FI}-40.1 \Delta \mathrm{MP}-41.8 \Delta \mathrm{EN}$ & 0.67 & 0.25 & 0.11 & 0.15 & 0.16 \\
\hline Italy & $\tilde{\mathrm{R}}=100-49.0 \Delta \mathrm{DU}-45.5 \Delta \mathrm{FI}-43.7 \Delta \mathrm{MP}-36.7 \Delta \mathrm{EN}$ & 0.71 & 0.20 & 0.18 & 0.18 & 0.15 \\
\hline Moldova & $\tilde{\mathrm{R}}=100-57.8 \Delta \mathrm{DU}-53.8 \Delta \mathrm{FI}-51.8 \Delta \mathrm{MP}-35.9 \Delta \mathrm{EN}$ & 0.75 & 0.22 & 0.20 & 0.19 & 0.14 \\
\hline Poland & $\tilde{\mathrm{R}}=100-74.9 \Delta \mathrm{DU}-66.9 \Delta \mathrm{FI}-64.2 \Delta \mathrm{MP}-61.5 \Delta \mathrm{EN}$ & 0.78 & 0.22 & 0.20 & 0.19 & 0.17 \\
\hline Romania & $\tilde{\mathrm{R}}=100-57.7 \Delta \mathrm{DU}-53.5 \Delta \mathrm{FI}-49.4 \Delta \mathrm{MP}-45.3 \Delta \mathrm{EN}$ & 0.74 & 0.21 & 0.19 & 0.18 & 0.16 \\
\hline Russia & $\tilde{\mathrm{R}}=100-78.9 \Delta \mathrm{DU}-73.3 \Delta \mathrm{FI}-70.5 \Delta \mathrm{MP}-59.2 \Delta \mathrm{EN}$ & 0.80 & 0.22 & 0.21 & 0.20 & 0.17 \\
\hline Scandinavia & $\tilde{\mathrm{R}}=100-47.4 \Delta \mathrm{DU}-44.1 \Delta \mathrm{FI}-42.5 \Delta \mathrm{MP}-29.4 \Delta \mathrm{EN}$ & 0.73 & 0.21 & 0.20 & 0.19 & 0.13 \\
\hline Slovakia & $\tilde{\mathrm{R}}=100-71.8 \Delta \mathrm{DU}-69.2 \Delta \mathrm{FI}-66.5 \Delta \mathrm{MP}-58.5 \Delta \mathrm{EN}$ & 0.79 & 0.21 & 0.21 & 0.20 & 0.17 \\
\hline Spain & $\tilde{\mathrm{R}}=100-47.5 \Delta \mathrm{DU}-45.7 \Delta \mathrm{FI}-44.0 \Delta \mathrm{MP}-38.7 \Delta \mathrm{EN}$ & 0.73 & 0.20 & 0.19 & 0.18 & 0.16 \\
\hline Turkey & $\tilde{\mathrm{R}}=100-54.1 \Delta \mathrm{DU}-38.9 \Delta \mathrm{FI}-45.6 \Delta \mathrm{MP}-30.4 \Delta \mathrm{EN}$ & 0.72 & 0.23 & 0.17 & 0.19 & 0.13 \\
\hline UK & $\tilde{\mathrm{R}}=100-50.0 \Delta \mathrm{DU}-48.3 \Delta \mathrm{FI}-41.4 \Delta \mathrm{MP}-32.8 \Delta \mathrm{EN}$ & 0.75 & 0.22 & 0.21 & 0.18 & 0.14 \\
\hline USA & $\tilde{\mathrm{R}}=100-48.1 \Delta \mathrm{DU}-41.9 \Delta \mathrm{FI}-38.8 \Delta \mathrm{MP}-26.4 \Delta \mathrm{EN}$ & 0.74 & 0.23 & 0.20 & 0.19 & 0.12 \\
\hline
\end{tabular}

countries and regions, was considered, but they can be numerous and at most in the context of an individual country or group of countries. For example, with decreasing cultural differences with Germany for these factors, respectively, $0.20,0.15,0.25,0.10$, the success of communication at the expense of each of them will increase accordingly: $\Delta R_{1}=0.20 \cdot 49.9=9.8 ; \Delta R_{2}=0.15 \cdot 43.2=6.5$; $\Delta \mathrm{R}_{3}=0.25 \cdot 41.6=10.4 ; \Delta \mathrm{R}_{4}=0.10 \cdot 31.6=3.2$ points; and all at $\Delta \mathrm{R}=$ 29.9 points. The predicted success of communication will be $\mathrm{R}=\mathrm{YR}+\Delta \mathrm{R}=40.1+29.9=70$ points. With a decrease in the same size of cultural differences with China, France and the United States, the success of communications will increase by 31.1, 32.3, 28.2 points, respectively and will amount to $54.2,82.1,60.5$ points, respectively.

Similar prediction calculations can be made in other countries and regions of the world with a set of different combinations of factor characteristics.

\section{Conclusions}

Business is a multicultural phenomenon and, therefore, entrepreneurs and managers cannot afford to take a guided look at the world through the prism of their own values and prospects: «our way of life and our values are the best and only possible, and everything else is not worthy of attention as something underdeveloped and imperfect». Mistake is also made by businessmen from all other cultures, depending on how similar they are to their own culture, which is perceived as correct, normal and superior to all other. It should be emphasized that the right to conduct international business and the implementation of cross-cultural communications is an approach based on the equal value of different cultures and the recognition of cultural differences as good, which ensures the harmony of the mankind existence. However, it is fair to point out that these differences lead one to disappointment, due to the difficulty of their perception, confusion and unpredictability. The proposed developments in the article, which are based on statistical measures and models, minimize confusion and create opportunities for quantitative perceptions of intercultural differences and the predictability of communication responses from the standpoint of the Ukrainian business culture. The obtained results of the study are new and can be used in development of the cross-cultural communication strategies, as well as in justifying the ways of adapting to different types of intercultural differences and improving the efficiency of communications in the process of business trips. 


\section{References}

[1] MARTYNYSHYN, Y., KOVALENKO, Y. Art of management and educational technologies of preparation of managers of social and cultural activity (in Ukrainian). Bila Tserkva: O. V. Pshonkivskyj, 2018. ISBN 978-617-604-144-3.

[2] FUNAKAWA, A. Transcultural management. A new approach for global organizations. San Francisco: Jossey-Bass, 1997. ISBN 978-078-790-323-7.

[3] MEAD, R. Cross-cultural management communication. Chichester: Wiley, 1992. ISBN 978-047-193-718-0.

[4] ADLER, N. J. Intermational dimensions of organizational behaviour. Boston: Cengage Learning, 2007. ISBN 978032-436-074-5.

[5] PRIMECZ, H., ROMANI, L., SACKMANN, S. Cross-cultural management in practice: culture and negotiated meanings. Cheltenham: Edward Elgar Pub, 2012. ISBN 978-184-980-407-3.

[6] LEWIS, R. Cross-cultural communication. London: Transcreen Publications, 2008. ISBN 978-095-343-983-6.

[7] NORALES, F. Cross-cultural communication: concepts, cases and challenges. New York: Cambria Press, 2006. ISBN 978-097-735-673-7.

[8] VARNER, I., BEAMER, L. Intercultural communication in the global workplace. New York: McGraw-Hill Education, 2010. ISBN 978-007-337-774-2.

[9] GESTELAND, R. Cross-cultural business behavior: a guide for global management. Copenhagen: CBS Press, 2012. ISBN 978-876-300-238-7.

[10] MARTYNYSHYN, Y., KOVALENKO, Y. Formation of the modern system management of life society. Bulletin of Kyiv National University of Culture and Arts. Series in Management of Social and Cultural Activity (in Ukrainian) [online]. 2018, 1, p. 7-24. ISSN 2616-7573, eISSN 2617-1104. Available from: https://doi.org/10.31866/2616-7573.1.2018.143383

[11] MEAD, R. International management: cross-cultural dimensions. Chichester: John Wiley and Sons Ltd, 1998. ISBN 978-063-120-003-1.

[12] MERKIN, R. S. Saving face in business: managing cross-cultural interactions. New York: Palgrave Macmillan, 2018. ISBN 978-113-759-173-9.

[13] REYNOLDS, S., VALENTINE, D. Guide to cross-cultural communication. Upper Saddle River: Prentice Hall, 2003. ISBN 978-013-049-784-0.

[14] ABRAHAM, B. Statistical methods for forecasting. New York: Wiley-Interscience, 2013. ISBN 978-047-176-987-3. 